\title{
Sorgenfrei in die Pensionierung blicken
}

Wissen Sie, welche Leistungen Ihnen nach der Pensionierung zustehen? Haben Sie berechnet, ob Sie sich eine Frühpensionierung leisten können? In einer Pensionsplanung zeigen wir Ihnen auf, wie Sie Ihren dritten Lebensabschnitt optimal finanzieren können. Wir berechnen Ihnen Ihre Leistungen aus den Sozialversicherungen und der beruflichen Vorsorge und zeigen Ihnen, wo Sie Ihre Steuern optimieren können. Gemeinsam erarbeiten wir ein Konzept, damit Sie sorgenfrei in die Zukunft blicken können.

\section{Sind Sie sicher?}

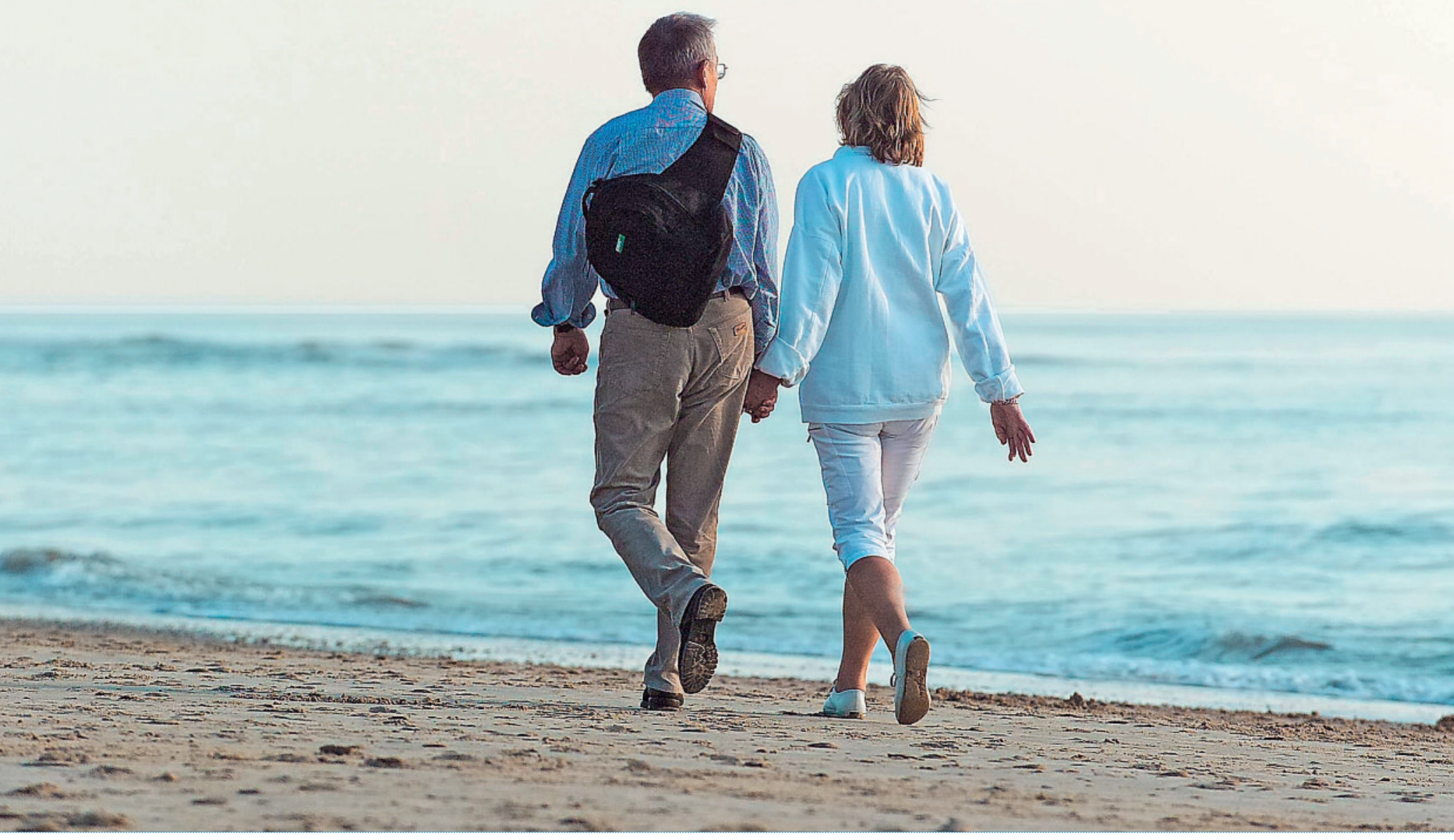

$\square$ Ich will mich auf meine Pensionierung freuen können und möchte mich beraten lassen. Bitte rufen Sie mich an.

\section{Vorname/Name}

Adresse

PLZ/Ort

\section{Geburtsdatum}

Telefon Privat/Geschäft

Beste Zeit für einen Anruf

E-Mail-Adresse 